\title{
KAJIAN PENATAAN SISTEM DRAINASE DAERAH TANGKAPAN PARIT M. SOHOR
}

\author{
Doddy Cahyadi Saputra ${ }^{1)}$, Nurhayati' ${ }^{2)}$, Aji Ali Akbar ${ }^{2)}$ \\ doddy.cs19@gmail.com
}

\begin{abstract}
Abstrak
Curah hujan dengan intensitas tinggi yang terjadi dalam beberapa waktu bisa menimbulkan genangan jika kondisi sistem drainasenya tidak terpelihara dengan baik. Perkembangan infrastruktur di Kota Pontianak memberikan dampak perubahan tata guna lahan yang mengakibatkan lahan yang semula berupa ruang hijau beralih fungsi menjadi kawasan permukiman dan kegiatan ekonomi lainnya. Kondisi eksisting saluran drainase atau parit di Jalan M. Sohor tidak mampu untuk menampung debit air hujan pada musim penghujan. Pada kondisi eksisting lahan di Kota Pontianak sudah tidak terdapat ruang resapan air hujan atau ruang terbuka hujan. Penataan sistem drainase Kota Pontianak dengan hanya menata drainasenya saja sudah tidak efektif lagi sehingga memerlukan konsep penataan sistem drainase yang berwawasan lingkungan. Maka dengan kondisi tersebut diperlukan indentifikasi terhadap kondisi hidrologi dan hidrolika yang ada di daerah tangkapan hujan Parit M. Sohor. Analisis hidrologi pada kajian ini meliputi pengujian konsistensi data hujan di Kota Pontianak, memilih distribusi hujan yang cocok dengan pola data hujan, menghitung waktu konsentrasi, intensitas curah hujan serta debit total rencana yang berasal dari debit buangan domestik dan debit rencana 2, 5, 10 tahun. Analisa hidrolika pada kajian ini meliputi pembuatan desain penampang saluran rencana sebagai rencana normalisasi saluran. Debit total di Parit M.Sohor untuk periode ulang 2 tahun adalah $2,22 \mathrm{~m}^{3} / \mathrm{s}$, periode ulang 5 tahun sebesar $2,75 \mathrm{~m}^{3} / \mathrm{s}$ dan periode ulang 10 tahun sebesar 3,09 $\mathrm{m}^{3} / \mathrm{s}$. Penataan drainase dengan konsep berwawasan lingkungan mengedepankan penataan drainase yang ramah lingkungan dengan menanam tanaman perdu yang dapat menahan erosi permukaan seperti tanaman Puring dan Bogenvil dan mereduksi polusi udara, menata Jalan M. Sohor mengendalikan debit air hujan berlebih yang diakibatkan oleh proses hujan melalui teknik rain water harvesting.
\end{abstract}

Kata Kunci: Hidrologi, Hidrolika, Drainase Berwawasan Lingkungan, Debit Air Hujan, Daerah Tangkapan Hujan

\begin{abstract}
High intensity rainfall that occurs can cause puddles if the condition of the drainage system is not well maintained. The development of Pontianak City Infrastructure has resulted in land use changes that was originally in the form of vacant land converted into residential areas or other economic activities. The existing condition of the drainage channel at M. Sohor Road is not able to accommodate rainwater discharge in the rainy season. In the existing conditions for land use, there is no rainwater catchment area. The management of floods with arranging the drainage system has been ineffective so we need an environmentally drainage system arrangement concept. Identification of the hydrological and hydrolic conditions that exist in the catchment area of the M. Sohor channel is required. The hydrological analysis in this study includes testing the consistency of rainfall data in Pontianak City, selecting a rain distribution that matches the rainfall data pattern, calculating the time concentration, rainfall intensity and the total discharge from domestic discharge and design discharge of 2, 5, 10 years. The hydraulic analysis in this study includes the design of a channel cross section design as a channel normalization plan. The total flow discharge in M.Sohor channel for a 2-year return period is $2.22 \mathrm{~m}^{3} / \mathrm{s}$, a 5 -year return period of $2.75 \mathrm{~m}^{3} / \mathrm{s}$ and a 10 -year return period of $3.09 \mathrm{~m}^{3} / \mathrm{s}$. Environmental insight drainage can be done by planting shrub plants that can reduce air pollution such as Croton and Bougainvillea, arranging M. Sohor Road to be friendly with pedestrians controlling excess rainwater discharge caused by the rain process through rain water harvesting techniques.
\end{abstract}

Keywords: Hydrological, Hydrolic, Environmental Insight Drainage, Rainwater Discharge, Catchment Area

\section{PENDAHULUAN}

\subsection{Latar Belakang}

Drainase-drainase yang sudah ada sebelumnya tidak memadai sebagai tempat penampungan air baik air hujan ataupun air buangan akibat aktivitas masyarakat sehari-hari sehingga diperlukan kajian untuk pengembangan prasarana perkotaan saluran drainase yang baik agar dapat menampung debit air hujan sehingga membuat genangan atau banjir khususnya di Kota Pontianak. Kota Pontianak merupakan kota dengan tingkat curah hujan yang cukup tinggi, maka penyusuan drainase perkotaan sangat 
diperlukan. Drainase kota yang kurang baik selama ini sering dijadikan alasan terjadinya banjir yang disebabkan oleh intensitas curah hujan yang tinggi, sehingga secara parsial penanggulangan masalah genangan atau banjir hanya dengan mengandalkan memperbanyak saluran drainase, padahal ditinjau dari pengelolaan siklus hujan, perencanaan drainase kota tidak hanya mengandalkan konsep pengaliran air saja, tetapi mengacu pada konsep konservasi air perkotaan (Kodoatie, 2003).

Peningkatan pembangunan jalan, bangunan, maupun sistem drainase diperlukan secara terarah dengan menyesuaikan berbagai infrastruktur yang telah ada. Kenyataan di lapangan saat ini prasarana dan sarana lingkungan pemukiman yang masih dirasakan masih kurang memenuhi persyaratan kualitas maupun kuantitas. Hal tersebut terlihat terutama pada musim penghujan saluran drainase yang ada sudah tidak bisa menampung air, sehingga akan terjadi genangan/banjir (Sukarto,1999).

Kota Pontianak yang dilalui oleh garis khatulistiwa, memiliki topografi relatif datar dan rendah dengan ketinggian rata-rata 0,10-1,05 meter di atas permukaan laut, sehingga dipengaruhi oleh pasang surut air laut, serta curah hujan yang tinggi menjadikan Kota Pontianak rentan terhadap genangan air atau banjir oleh pasang ataupun hujan. Curah hujan dengan intensitas tinggi yang terjadi dalam beberapa waktu bisa menimbulkan genangan jika sistem drainasenya tidak terpelihara baik (Mulyani, 2017).

\subsection{Perumusan Masalah}

Perkembangan infrastruktur di Kota Pontianak memberikan dampak perubahan tata guna lahan yang mengakibatkan lahan yang semula berupa lahan kosong atau lahan kebun beralih fungsi menjadi kawasan permukiman dan kegiatan ekonomi lainnya. Kawasan yang semula berfungsi sebagai daerah resapan air, khususnya di saluran Jalan M. Sohor sudah tidak mampu untuk menampung debit air hujan pada musim penghujan. Penyelenggaraan sistem drainase perkotaan penanggan banjir dengan kondisi penataan sistem drainase sudah tidak efektif sehingga memerlukan konsep penataan sistem drainase yang berwawasan lingkungan. Rumusan masalah dalam penelitian ini adalah bagaimana penataaan sistem drainase pada lokasi tersebut.

\subsection{Tujuan Penelitian}

Tujuan yang ingin dicapai dalam penelitian ini adalah:

1. Mengidentifikasi kondisi hidrologi dan hidrolika yang ada pada sistem drainase di wilayah studi.

2. Menata sistem saluran drainase yang ada dengan konsep yang berwawasan lingkungan

\subsection{Manfaat Penelitian}

Penelitian ini diharapkan bermanfaat untuk menambah wawasan dalam bidang pengelolaan dan pengembangan infrastruktur, khususnya yang berkaitan dengan penentuan sistem drainase yang berwawasan lingkungan.

\section{METODOLOGI PENELITIAN}

2.1. Lokasi Penelitian

Penelitian ini dilakukan pada catchment area M. Sohor. Lokasi penelitian secara administrasi masuk dalam wilayah Kecamatan Pontianak Selatan 

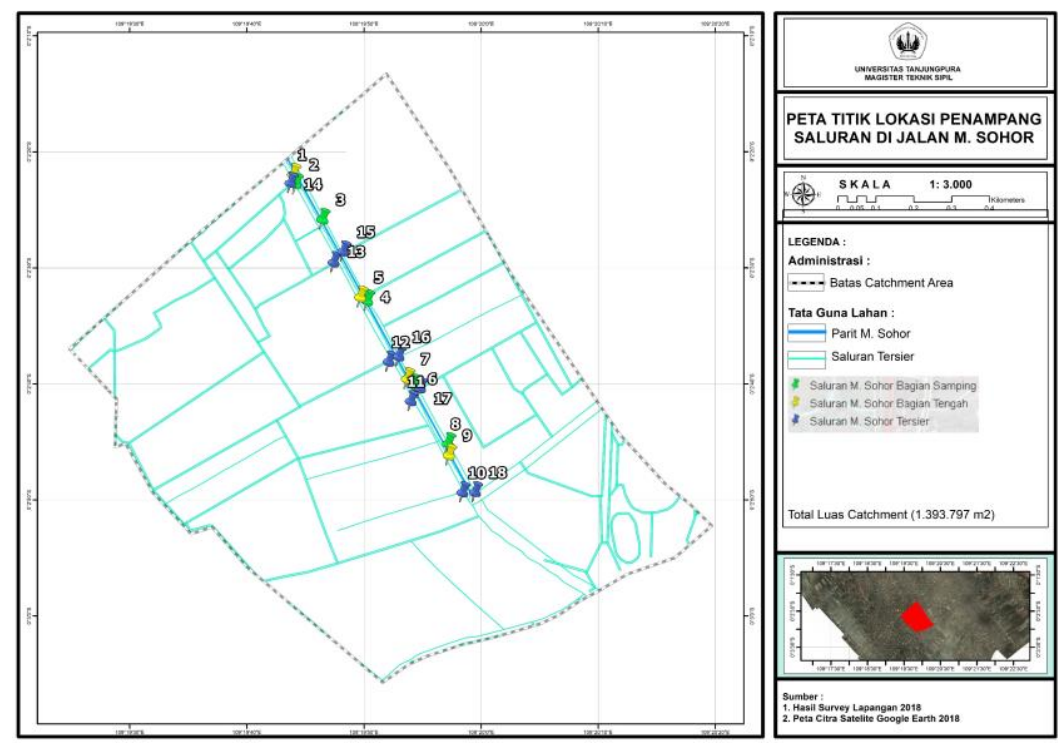

Gambar 1. Lokasi penelitian.

2.2. Alur Penelitian

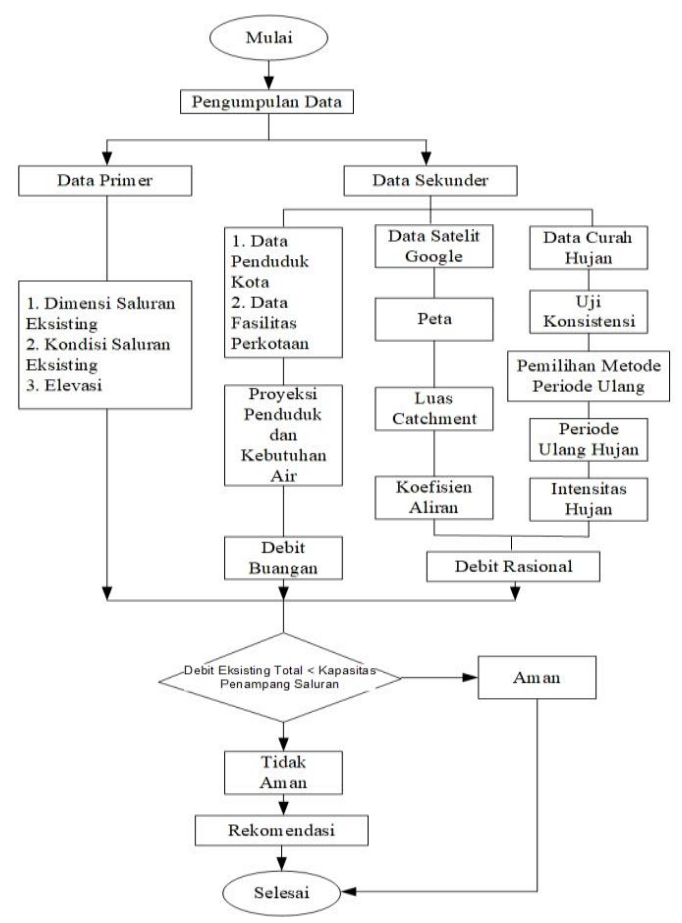

Gambar 2. Alur penelitian

\subsection{Pengumpulan Data}

Data yang dikumpulkan, yaitu data primer dan data sekunder. Data primer dikumpulkan melalui pengamatan langsung di lokasi penelitian meliputi penampang saluran (lebar dan dalam), kecepatan aliran dan kondisi eksisting drainase. Data sekunder adalah data yang diperoleh dari instansi/pihak terkait, seperti peta lokasi penelitian, data curah hujan, data kependudukan, dan lain-lain.

\subsection{Peralatan yang Digunakan}

Alat yang digunakan untuk melakukan survey hidrometri adalah current meter Global Water FP-111, rambu ukur, meteran dan Garmin GPSMAP 64sc.

\subsection{Tahapan Analisis Hidrologi}

Perhitungan hidrologi pada ruang lingkup

kajian dilakukan melalui tahap sebagai berikut :

1. Melakukan uji konsistensi data curah hujan menggunakan metode Rescaled Adjusted Partial Sum (RAPS) (Harto, 2000).

2. Melakukan pengujian model distribusi hujan yang cocok pada data hujan ruang lingkup kajian dengan pengujian statistik dan pengujian Chi Kuadrat. Kedua pengujian tersebut akan menguji kecocokan dari 5 model distribusi data curah hujan, yaitu distribusi normal, distribusi gumbel tipe I, distribusi log pearson III, distribusi log normal 2 dan distribusi log normal 3.

3. Distribusi curah hujan yang paling cocok akan disajikan dalam 6 data dengan periode ulang 2 tahun, 5 tahun, 10 tahun, 25 tahun, 50 tahun dan 100 tahun (Soewarno, 1995).

4. Menghitung nilai waktu konsentrasi saluran dengan metode Kirprich pada masingmasing periode ulang hujan (Suripin, 2004).

5. Menghitung nilai intensitas hujan dengan metode Mononobe pada masing-masing periode ulang hujan (Suripin, 2004).

6. Menghitung debit banjir rencana dengan metode Rasional pada masing-masing debit rencana hujan periode ulang 2 tahun, 5 tahun, 10 tahun, 25 tahun, 50 tahun dan 100 tahun. Koefisien pengaliran pada ruang lingkup kajian diambil dari hasil digitasi 
sesuai dengan jenis penggunaan lahan (Soemarto, 1995).

7. Memproyeksikan data penduduk Kelurahan Akcaya sebanyak 20 tahun untuk menentukan kebutuhan debit domestik dan domestik yang akan diambil sebesar $70 \%$ nilainya sebagai debit buangan yang disalurkan pada saluran pembuangan sebagai Qbuangan (Soemarto, 1995).

\subsection{Tahapan Analisis Hidrolika}

Perhitungan hidrologi pada ruang lingkup kajian dilakukan melalui tahap sebagai berikut :

1. Menentukan debit banjir rencana dengan periode ulang 10 tahunan $\left(\mathrm{Q}_{10}\right)$

2. Menentukan kecepatan minimum aliran $\left(\mathrm{v}_{\text {minimum }}\right)$ rencana.

3. Menghitung luas penampang $A=\frac{Q}{v}$

4. Menentukan bentuk penampang saluran yang direncanakan. Bentuk penampang yang dipilih adalah bentuk persegi

5. Menentukan lebar (b) dan kedalaman (h) digunakan trial and error atau coba-coba. Diambil nilai $\mathrm{b}$, maka nilai $\mathrm{h}$ dapat dihitung. $A=b \times h$

$$
h=\frac{A}{b}
$$

6. Menghitung keliling basah penampang saluran $(\mathrm{P})$

$$
P=b+2 h
$$

7. Menghitung jari-jari hidrolis penampang saluran $(\mathrm{R})$

$$
R=\frac{A}{P}
$$

8. Menghitung kemiringan dasar saluran minimum $\left(S_{\text {minimum }}\right)$ menggunakan rumus dasar Manning:

$$
\begin{aligned}
& Q=\frac{1}{n} \times R^{2 / 3} \times S_{\min }^{1 / 2} \times A \ldots \ldots \ldots . . \\
& S_{\min }=\left[\frac{Q \times n}{R^{2 / 3} \times A}\right]^{2} \ldots \ldots \ldots \ldots \ldots . . .
\end{aligned}
$$

9. Menentukan tinggi jagaan (W) untuk debit desain $\left(\mathrm{Q}_{10}\right)$ berdasarkan tabel tinggi jagaan, maka tinggi saluran total $=\mathrm{h}+$ tinggi jagaan (W)

$$
h_{\text {total }}=h+W
$$

10.Membandingkan debit desain terhadap debit rencana $\left(\mathrm{Q}_{10}\right)$, dimana dimensi saluran akan aman jika $Q_{\text {desain }}>Q_{\text {rencana }}+Q_{\text {buangan. }}$

\section{ANALISA DATA DAN PEMBAHASAN}

3.1. Kondisi Eksisting Jaringan Drainase Parit M. Sohor

Kegiatan survei dilakukan di daerah tangkapan hujan Parit M. Sohor dengan menelusuri trase alur Parit Tengah M. Sohor hanya terbuka sampai di depan Jalan Dr. Rubini, untuk trase alur seterusnya berada tertutup di bawah perkerasan jalan yang diteruskan pembuangannya sampai ke Parit Tokaya yang berperan sebagai saluran primer, sehingga dapat dikatakan Parit M. Sohor sebagai saluran sekunder. Hal ini terlihat dalam pengamatan di lapangan, arus debit buangan mengalir ke arah saluran Parit Tokaya.

Pengambilan data penampang saluran diambil sebanyak 9 titik di drainase sekunder dengan data penampang saluran tengah sebanyak 4 titik dan data penampang saluran samping sebanyak 5 titik sebagai pendukung analisis sistem jaringan drainase yang berwawasan

\begin{tabular}{|c|c|c|c|c|c|c|}
\hline \multirow[b]{2}{*}{ Titik } & \multirow[b]{2}{*}{$\begin{array}{c}\text { Lintang } \\
\text { Selatan (LS) }\end{array}$} & \multirow[b]{2}{*}{$\begin{array}{l}\text { Bujur Timur } \\
\text { (BT) }\end{array}$} & \multicolumn{4}{|c|}{ Dimensi Eksisting Saluran } \\
\hline & & & $\begin{array}{c}\text { Lebar } \\
\text { Atas } \\
\text { (m) }\end{array}$ & $\begin{array}{c}\text { Lebar } \\
\text { Bawah } \\
\text { (m) }\end{array}$ & $\begin{array}{c}\text { Ting } \\
\text { gi } \\
(\mathrm{m})\end{array}$ & $\begin{array}{l}\text { Luas } \\
\left(\mathrm{m}^{2}\right)\end{array}$ \\
\hline 1 & $00^{\circ} 02^{\prime} 21,90^{\prime \prime}$ & $109^{\circ} 19^{\prime} 44,29^{\prime \prime}$ & 2,40 & 1,40 & 1,30 & 2,47 \\
\hline 2 & $00^{\circ} 02^{\prime} 22,75^{\prime \prime}$ & $109^{\circ} 19^{\prime} 44,49^{\prime \prime}$ & 0,6 & 0,6 & 0,65 & 0,39 \\
\hline 3 & $00^{\circ} 02^{\prime} 25,77^{\prime \prime}$ & $109^{\circ} 19^{\prime} 46,78^{\prime \prime}$ & 2,40 & 1,40 & 1,30 & 2,47 \\
\hline 4 & $00^{\circ} 02^{\prime} 32,79^{\prime \prime}$ & $109^{\circ} 19^{\prime} 50,60^{\prime \prime}$ & 0,65 & 0,65 & 0,8 & 0,52 \\
\hline 5 & $00^{\circ} 02^{\prime} 32,47^{\prime \prime}$ & $109^{\circ} 19^{\prime} 50,02^{\prime \prime}$ & 2,40 & 1,40 & 1,30 & 2,47 \\
\hline 6 & $00^{\circ} 02^{\prime} 40,07^{\prime \prime}$ & $109^{\circ} 19^{\prime} 54,61^{\prime \prime}$ & 1 & 1 & 0,9 & 0,9 \\
\hline 7 & $00^{\circ} 02^{\prime} 39,51^{\prime \prime}$ & $109^{\circ} 19^{\prime} 54,02^{\prime \prime}$ & 2,65 & 1,85 & 0,95 & 2,14 \\
\hline 8 & $00^{\circ} 02^{\prime} 45,10^{\prime \prime}$ & $109^{\circ} 19^{\prime} 57,52^{\prime \prime}$ & 1,2 & 1,2 & 0,4 & 0,48 \\
\hline 9 & $00^{\circ} 02^{\prime} 46,09^{\prime \prime}$ & $109^{\circ} 19^{\prime} 57,58^{\prime \prime}$ & 3,00 & 2,40 & 0,80 & 2,16 \\
\hline 10 & $00^{\circ} 02^{\prime} 49,32^{\prime \prime}$ & $109^{\circ} 19^{\prime} 58,74^{\prime \prime}$ & 1,50 & 1,00 & 0,80 & 1,00 \\
\hline 11 & $00^{\circ} 02^{\prime} 41,45^{\prime \prime}$ & $109^{\circ} 19^{\prime} 54,32^{\prime \prime}$ & 0,62 & 0,62 & 0,8 & 0,496 \\
\hline 12 & $00^{\circ} 02^{\prime} 38,05^{\prime \prime}$ & $109^{\circ} 19^{\prime} 52,43^{\prime \prime}$ & 0,6 & 0,6 & 0,45 & 0,27 \\
\hline 13 & $00^{\circ} 02^{\prime} 29,48^{\prime \prime}$ & $109^{\circ} 19^{\prime} 47,73^{\prime \prime}$ & 0,9 & 0,9 & 0,55 & 0,495 \\
\hline 14 & $00^{\circ} 02^{\prime} 22,65^{\prime \prime}$ & $109^{\circ} 19^{\prime} 44,04^{\prime \prime}$ & 0,6 & 0,6 & 0,65 & 0,39 \\
\hline \multirow[t]{2}{*}{15} & $00^{\circ} 02^{\prime} 28,55^{\prime \prime}$ & $109^{\circ} 19^{\prime} 48,55^{\prime \prime}$ & 0,95 & 0,95 & 0,4 & 0,38 \\
\hline & & & 1,50 & 0,95 & 0,75 & 0,92 \\
\hline 16 & $00^{\circ} 02^{\prime} 37,60^{\prime \prime}$ & $109^{\circ} 19^{\prime} 53,28^{\prime \prime}$ & 0,85 & 0,85 & 0,9 & 0,765 \\
\hline \multirow[t]{2}{*}{17} & $00^{\circ} 02^{\prime} 40,34^{\prime \prime}$ & $109^{\circ} 19^{\prime} 55,12^{\prime \prime}$ & 0,9 & 0,9 & 0,95 & 0,855 \\
\hline & & & 1,45 & 0,80 & 0,95 & 1,07 \\
\hline 18 & $00^{\circ} 02^{\prime} 49,29^{\prime \prime}$ & $109^{\circ} 19^{\prime} 59,80^{\prime \prime}$ & 0,85 & 0,85 & 0,65 & 0,553 \\
\hline
\end{tabular}
lingkungan pada catchment area Parit M. Sohor. Pengambilan titik pada jaringan drainase tersier di sepanjang Parit M. Sohor dengan jumlah sebanyak 9 titik dari titik 10 - titik 18 .

Tabel 1. Koordinat Survei Penampang Parit M. Sohor

\subsection{Analisis Hidrologi}

\subsubsection{Uji Konsistensi}

Data curah hujan yang digunakan bersumber dari Stasiun Meteorologi Supadio Pontianak dari tahun 1999 - 2017 dengan jumah data 19 tahun. Pada tabel derajat kepercayaan tidak terdapat $\mathrm{n}=19$ untuk setiap nilai derajat kepercayaan sehingga dilakukan interpolasi pada 
nilai $\mathrm{Q} / \sqrt{\mathrm{N}}$ untuk $\mathrm{n}=19$ di nilai derajat kepercayaan $90 \%$ yang menghasilkan nilai interpolasi Q kritis 1,095.

Hasil pengujian konsistensi data dari metode Rescaled Adjusted Partial Sum, nilai Q hitung $/ \sqrt{ }$ n $(1,081)$ tidak melebihi nilai $Q$ kritis $(1,095)$ di tabel interpolasi sehingga data tersebut dapat dikategorikan konsisten.

\subsubsection{Pemilihan Model Distribusi Hujan}

Analisis distribusi yang dilakukan bertujuan untuk mengetahui metode yang cocok dengan pola distribusi data yang terlampir. Pengujian yang dilakukan adalah dengan pengujian parameter statistik dan pengujian Chi Kuadrat.

Tabel 2. Nilai Deskriptor Statistik Masing-Masing Metode

\begin{tabular}{ccccccccc}
\hline \multirow{2}{*}{ Hasil Perhitungan } & \multirow{2}{*}{ Normal } & $\begin{array}{c}\text { Gumbel } \\
\text { Tipe I }\end{array}$ & \multicolumn{2}{c}{$\begin{array}{c}\text { Hasil Perhitungan } \\
\text { Log }\end{array}$} & $\begin{array}{c}\text { Log } \\
\text { Pearson }\end{array}$ & $\begin{array}{c}\text { Log } \\
\text { Normal 2 }\end{array}$ & $\begin{array}{c}\text { Log Normal 3 } \\
\text { Parameter }\end{array}$ \\
\hline SD & 29,9828 & 29,9828 & 29,9828 & SD & 0,1032 & 0,1032 & 0,1032 & 0,1032 \\
Cs & 1,2526 & 0,0000 & 1,1390 & Cs & 0,1032 & 0,6637 & 0,1507 & 0,7020 \\
Ck & 1,3819 & 3,0000 & 5,4020 & Ck & 0,4596 & 0,4596 & 3,0404 & 3,8000 \\
Cv & 0,2567 & 0,2567 & 0,2567 & $\mathrm{Cv}$ & 0,0502 & 0,0000 & 0,0502 & 0,0502 \\
\hline
\end{tabular}

Tabel 3. Syarat Pengambilan Metode dari Perhitungan Deskriptor Statistik Masing - Masing Metode

\begin{tabular}{cccccc}
\hline $\begin{array}{c}\text { Hasil } \\
\text { Perhitungan }\end{array}$ & Normal & Gumbel Tipe I & $\begin{array}{c}\text { Log Pearson } \\
\text { Tipe III }\end{array}$ & $\begin{array}{c}\text { Log Normal 2 } \\
\text { Parameter }\end{array}$ & $\begin{array}{c}\text { Log Normal 3 } \\
\text { Parameter }\end{array}$ \\
\hline Cs & Tidak & Temenuhi & Tidak Memenuhi Tidak Memenuhi & $\begin{array}{c}\text { Tidak } \\
\text { Memenuhi }\end{array}$ & Tidak Memenuhi \\
Ck & Memenuhi & Memenuhi & Tidak Memenuhi & Memenuhi & Memenuhi \\
\hline
\end{tabular}

Tabel 4. Hasil pengujian Chi Kuadrat $\left(\chi^{2}\right)$ Terhadap Data Curah Hujan yang diuji Berdasarkan Peluang Uji Untuk Metode Gumbel Tipe I

\begin{tabular}{|c|c|c|c|c|c|c|c|c|c|c|}
\hline Metode & Peluang & Nila & i Batas & $\mathbf{O i}$ & $\mathbf{E i}$ & $(\mathrm{Oi}-\mathrm{Ei})^{2}$ & $\chi h^{2}$ & Keputusan & dk & $\chi h^{2}$ tabel \\
\hline & $\mathrm{P}=1-0,8=0,2$ & $\mathrm{x}$ & $<92,1816$ & 3 & 4 & 1 & 0,17 & \multirow{6}{*}{ DITERIMA } & \multirow{6}{*}{4} & \multirow{6}{*}{2,173833} \\
\hline & $P=1-0,6=0,4$ & x 92,1816 & - 105,3385 & 4 & 4 & 0 & 0,01 & & & \\
\hline Gumbel & $P=1-0,4=0,6$ & X 105,3385 & - 118,9862 & 6 & 4 & 5 & 1,27 & & & \\
\hline \multirow[t]{3}{*}{ Tipe I } & $\mathrm{P}=1-0,2=0,8$ & X 118,9862 & - 138,5930 & 3 & 4 & 1 & 0,17 & & & \\
\hline & & & $>138,5930$ & 3 & 4 & 1 & 0,17 & & & \\
\hline & & & Jumlah & 19 & 19 & & 1,79 & & & \\
\hline
\end{tabular}

\subsubsection{Periode Ulang Hujan}

Pengujian Chi Kuadrat dan Statistik menunjukkan metode analisis distribusi hujan yang paling sesuai (Uji Kecocokan) adalah Metode Gumbel Tipe I yang mana dari metode tersebut digunakan untuk mencari periode ulang hujan 2, 5, 10, 25, 50 dan 100 tahun $\left(\mathrm{R}_{2}, \mathrm{R}_{5}, \mathrm{R}_{10}\right.$, $\mathrm{R}_{25}, \mathrm{R}_{50}$ dan $\mathrm{R}_{100}$ ).
Tabel 5. Periode Ulang Hujan Stasiun Stasiun Meteorologi Supadio Pontianak

\begin{tabular}{cc}
\hline $\begin{array}{c}\text { Periode } \\
\text { Ulang }\end{array}$ & $\mathrm{R}(\mathrm{mm})$ \\
\hline $\mathrm{R}_{2}$ & 111,8586 \\
$\mathrm{R}_{5}$ & 138,593 \\
$\mathrm{R}_{10}$ & 155,8862 \\
$\mathrm{R}_{25}$ & 176,3343 \\
$\mathrm{R}_{50}$ & 194,4455 \\
$\mathrm{R}_{100}$ & 210,804 \\
\hline
\end{tabular}

3.2.4. Intensitas Hujan

Intensitas hujan dihitung menggunakan metode Mononobe dengan kecepatan air di 
saluran diambil 0,6 m/s untuk kecepatan aliran di atas permukaan tanah lanau alluvial sesuai dengan lokasi eksisting.

Tabel 5. Hasil Perhitungan Intensitas Hujan

\begin{tabular}{cccc}
\hline $\begin{array}{c}\text { Periode } \\
\text { Ulang }\end{array}$ & $\mathrm{R}(\mathrm{mm})$ & $\begin{array}{c}\text { Intensitas } \\
\text { Hujan }\end{array}$ & $\begin{array}{c}\mathrm{I} \\
\text { (mm/jam) }\end{array}$ \\
\hline $\mathrm{R}_{2}$ & 111,859 & $\mathrm{I}_{2}$ & 15,046 \\
$\mathrm{R}_{5}$ & 138,593 & $\mathrm{I}_{5}$ & 18,642 \\
$\mathrm{R}_{10}$ & 155,886 & $\mathrm{I}_{10}$ & 20,968 \\
$\mathrm{R}_{25}$ & 176,334 & $\mathrm{I}_{25}$ & 23,718 \\
$\mathrm{R}_{50}$ & 194,446 & $\mathrm{I}_{50}$ & 26,154 \\
$\mathrm{R}_{100}$ & 210,804 & $\mathrm{I}_{100}$ & 28,354 \\
\hline
\end{tabular}

\subsubsection{Debit Rencana}

Hasil digitasi daerah sekitar catchment area pada Gambar 3 menunjukkan bahwa terdapat 3 nilai $\mathrm{C}$, yaitu tipe daerah ruang terbuka hijau (warna hijau pada Gambar 3) dengan jenis tanah gemuk (datar $2 \%)=0,15$ dan luas sebesar $796.750 \mathrm{~m}^{2}$; tipe daerah bangunan (warna kuning pada Gambar 3) "Multi Units" (tertutup) $=0,65$ dan luas sebesar $494.550 \mathrm{~m}^{2}$; dan jalan (warna abu-abu pada Gambar 3) beton $=0,85$ dan luas sebesar $102.497 \mathrm{~m}^{2}$.
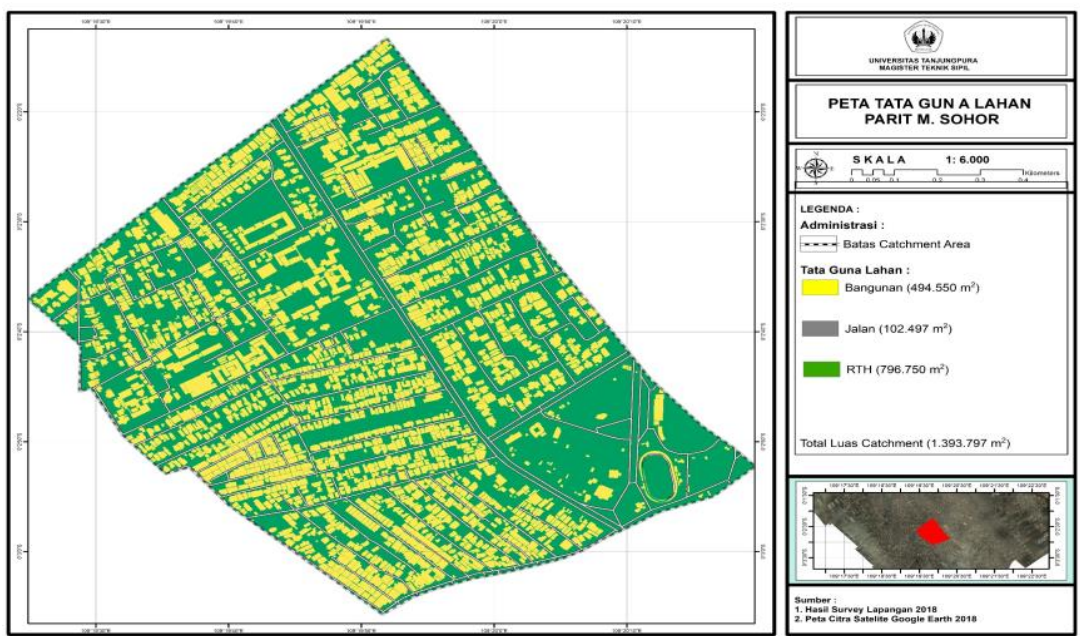

Gambar 3. Peta tata guna lahan Parit M. Sohor.

\subsubsection{Debit Rencana Total}

Debit rencana total didapatkan dari debit rencana hujan masing-masing periode ulang hujan yaitu periode ulang hujan 2 tahun, 5 tahun, 10 tahun, 25 tahun, 50 tahun dan 100 tahun yang ditambah dengan proyeksi debit kebutuhan air untuk 20 tahun ke depan sebesar $70 \%$ untuk proyeksi debit buangan.

Tabel 6. Hasil Debit Total

\begin{tabular}{cccccccc}
\hline \multicolumn{2}{c}{ Debit I (mm/jam) } & A $\left(\mathrm{km}^{2}\right)$ & $\mathrm{C}$ & $\begin{array}{c}\text { Q } \\
\left(\mathrm{m}^{3} / \mathrm{s}\right)\end{array}$ & $\begin{array}{c}\left.\mathrm{Q}_{\text {buangan }} / \mathrm{s}\right) \\
\mathrm{Q}_{2}\end{array}$ & $\begin{array}{c}\mathrm{Q}_{\text {total }} \\
\left(\mathrm{m}^{3} / \mathrm{s}\right)\end{array}$ \\
$\mathrm{Q}_{5}$ & 18,046 & 1,394 & 0,379 & 2,207 & 0,015 & 2,223 \\
$\mathrm{Q}_{10}$ & 20,968 & 1,394 & 0,379 & 2,735 & 0,015 & 2,750 \\
$\mathrm{Q}_{25}$ & 23,718 & 1,394 & 0,379 & 3,076 & 0,015 & 3,091 \\
$\mathrm{Q}_{50}$ & 26,154 & 1,394 & 0,379 & 3,479 & 0,015 & 3,495 \\
$\mathrm{Q}_{100}$ & 28,354 & 1,394 & 0,379 & 3,837 & 0,015 & 3,852 \\
\hline
\end{tabular}

Tabel 7. Perbandingan Debit Eksisting dan Debit Total Periode Ulang 2 Tahun untuk Parit M. Sohor

\begin{tabular}{ccccccccc}
\hline \multirow{3}{*}{ Spot } & \multicolumn{3}{c}{ Dimensi Eksisting Saluran } & Kecepatan \\
\cline { 2 - 6 } & $\begin{array}{c}\text { Lebar } \\
\text { Atas }(\mathrm{m})\end{array}$ & $\begin{array}{c}\text { Lebar } \\
\text { Bawah }(\mathrm{m})\end{array}$ & $\begin{array}{c}\text { Tinggi } \\
\text { Air }(\mathrm{m})\end{array}$ & $\begin{array}{c}\text { Debit } \\
\text { Luas }\left(\mathrm{m}^{2}\right)\end{array}$ & $\begin{array}{c}\text { Eksing } \\
(\mathrm{m} / \mathrm{s})\end{array}$ & $\begin{array}{c}\text { Eksisting } \\
\left(\mathrm{m}^{3} / \mathrm{s}\right)\end{array}$ & $\begin{array}{c}\text { Debit Total } \\
\left(\mathrm{m}^{3} / \mathrm{s}\right)\end{array}$ & Aman/Tidak \\
\hline 1 & 2,40 & 1,40 & 0,30 & 0,56 & 0,01 & 0,005 & 2,2225 & Tidak Aman \\
5 & 2,40 & 1,40 & 0,31 & 0,59 & 0,01 & 0,005 & 2,2225 & Tidak Aman \\
7 & 2,65 & 1,85 & 0,15 & 0,34 & 0,01 & 0,003 & 2,2225 & Tidak Aman \\
9 & 3,00 & 2,40 & 0,14 & 0,36 & 0,01 & 0,003 & 2,2225 & Tidak Aman \\
\hline
\end{tabular}

\subsection{Analisis Hidrolika}

3.3.1. Kondisi Penampang Parit M. Sohor

Perbandingan debit eksisting dan debit total periode ulang 2 tahun, 5 tahun dan 10 tahun menghasilkan kondisi yang tidak aman dimana kapasitas eksisting tidak dapat memenuhi debit total dari akumulasi air hujan dan debit buangan. Hal ini dikarenakan kondisi tata guna lahan yang masih kurang ruang terbuka hijau sehingga diperlukan suatu rekomendasi rancangan perbesaran dimensi drainase agar debit yang tertampung dapat mencukupi debit total rencana. 
Tabel 8. Perbandingan Debit Eksisting dan Debit Total Periode Ulang 5 Tahun untuk Parit M. Sohor

\begin{tabular}{|c|c|c|c|c|c|c|c|c|}
\hline \multirow[b]{2}{*}{ Spot } & \multicolumn{4}{|c|}{ Dimensi Eksisting Saluran } & \multirow{2}{*}{$\begin{array}{c}\text { Kecepatan } \\
\text { Eksisting } \\
(\mathrm{m} / \mathrm{s})\end{array}$} & \multirow{2}{*}{$\begin{array}{c}\text { Debit } \\
\text { Eksisting } \\
\left(\mathrm{m}^{3} / \mathrm{s}\right)\end{array}$} & \multirow{2}{*}{$\begin{array}{l}\text { Debit Total } \\
\left(\mathrm{m}^{3} / \mathrm{s}\right)\end{array}$} & \multirow[b]{2}{*}{ Aman/Tidak } \\
\hline & $\begin{array}{c}\text { Lebar } \\
\text { Atas (m) }\end{array}$ & $\begin{array}{c}\text { Lebar } \\
\text { Bawah (m) }\end{array}$ & $\begin{array}{l}\text { Tinggi } \\
\text { Air }(\mathrm{m})\end{array}$ & Luas $\left(\mathrm{m}^{2}\right)$ & & & & \\
\hline 1 & 2,40 & 1,40 & 0,30 & 0,56 & 0,01 & 0,005 & 2,7500 & Tidak Aman \\
\hline 5 & 2,40 & 1,40 & 0,31 & 0,59 & 0,01 & 0,005 & 2,7500 & Tidak Aman \\
\hline 7 & 2,65 & 1,85 & 0,15 & 0,34 & 0,01 & 0,003 & 2,7500 & Tidak Aman \\
\hline 9 & 3,00 & 2,40 & 0,14 & 0,36 & 0,01 & 0,003 & 2,7500 & Tidak Aman \\
\hline
\end{tabular}

Tabel 9. Perbandingan Debit Eksisting dan Debit Total Periode Ulang 10 Tahun untuk Parit M. Sohor

\begin{tabular}{ccccccccc}
\hline \multirow{2}{*}{ Spot } & \multicolumn{3}{c}{ Dimensi Eksisting Saluran } & $\begin{array}{c}\text { Kecepatan } \\
\text { Eksisting } \\
(\mathrm{m} / \mathrm{s})\end{array}$ & $\begin{array}{c}\text { Debit } \\
\text { Eksisting } \\
\left(\mathrm{m}^{3} / \mathrm{s}\right)\end{array}$ & $\begin{array}{c}\text { Debit Total } \\
\left(\mathrm{m}^{3} / \mathrm{s}\right)\end{array}$ & Aman/Tidak \\
\hline 1 & 2,40 & 1,40 & 0,30 & 0,56 & 0,01 & 0,005 & 3,0912 & Tidak Aman \\
5 & 2,40 & 1,40 & 0,31 & 0,59 & 0,01 & 0,005 & 3,0912 & Tidak Aman \\
7 & 2,65 & 1,85 & 0,15 & 0,34 & 0,01 & 0,003 & 3,0912 & Tidak Aman \\
9 & 3,00 & 2,40 & 0,14 & 0,36 & 0,01 & 0,003 & 3,0912 & Tidak Aman \\
\hline
\end{tabular}

\subsubsection{Desain Penampang Parit M. Sohor}

Rerata kemiringan (slope) yang ada di eksisting Parit M. Sohor sebesar 0,055 sedangkan untuk kemiringan disain sebesar 0,0129. Kondisi ini menunjukkan kondisi eksisting memiliki kemiringan dasar saluran yang relatif datar sehingga perlu dilakukan normalisasi terhadap saluran Parit M. Sohor bagian tengah agar kondisi kemiringan disain sebesar 0,0129 dapat terpenuhi.

Tata guna lahan daerah kajian harus dijaga agar run off yang terjadi tidak terlalu besar akibat dari koefisien run off (C) yang dapat menjadi besar akibat dari perubahan tata guna lahan dari ruang terbuka hijau menjadi jalan atau bangunan. Normalisasi perlu dilakukan agar dapat menjaga drainase terhindar dari proses pengendapan yang mengakibatkan debit penampungan berkurang dan aliran terhambat. Penataan drainase dengan konsep berwawasan lingkungan dapat melakukan penghijauan di sekitar area yang memiliki koefisien run off yang tinggi yaitu sekitar jalan raya dan bangunan agar penyerapan dapat terjadi dengan baik.

Tabel 10. Dimensi Penampang Parit M. Sohor

\begin{tabular}{|c|c|c|c|c|c|c|c|c|c|c|c|c|c|c|c|c|c|}
\hline Titik & $\begin{array}{l}\text { Debit } \\
\text { Total } \\
\left(\mathrm{m}^{3} / \mathrm{s}\right)\end{array}$ & $\begin{array}{l}V_{\text {min }} \\
(\mathrm{m} / \mathrm{s})\end{array}$ & $\begin{array}{c}A_{\text {rencana }} \\
\left(\mathrm{m}^{2}\right)\end{array}$ & $\mathrm{b}(\mathrm{m})$ & $\mathrm{a}(\mathrm{m})$ & $\mathrm{h}(\mathrm{m})$ & $\begin{array}{l}\mathrm{h}_{\text {disain }} \\
(\mathrm{m})\end{array}$ & $\begin{array}{c}\mathrm{W}_{\text {disain }} \\
(\mathrm{m})\end{array}$ & $\begin{array}{c}\mathrm{A}_{\text {disain }} \\
\left(\mathrm{m}^{2}\right)\end{array}$ & $\begin{array}{c}\mathrm{X}_{\text {disain }} \\
(\mathrm{m})\end{array}$ & $\begin{array}{c}P_{\text {disain }} \\
(\mathrm{m})\end{array}$ & $\begin{array}{c}\mathrm{R}_{\mathrm{disain}} \\
(\mathrm{m})\end{array}$ & $\begin{array}{c}\mathrm{Q}_{\text {disain }} \\
\left(\mathrm{m}^{3}\right)\end{array}$ & $\mathrm{n}$ & $S_{\text {hitung }}$ & $\mathrm{S}_{\text {eksisting }}$ & Status \\
\hline 1 & 2,7500 & 0,60 & 4,5834 & 1,40 & 2,40 & 2,4123 & 2,50 & 0,60 & 5,89 & 0,16 & 7,68 & 0,7669 & 3,5340 & 0,0180 & 0,0129 & 0,0550 & $\begin{array}{l}\text { Beda Tinggi } \\
\text { Memenuhi }\end{array}$ \\
\hline 5 & 2,7500 & 0,60 & 4,5834 & 1,40 & 2,40 & 2,4123 & 2,50 & 0,60 & 5,89 & 0,16 & 7,68 & 0,7669 & 3,5340 & 0,0180 & 0,0129 & 0,0550 & $\begin{array}{l}\text { Beda Tinggi } \\
\text { Memenuhi }\end{array}$ \\
\hline 7 & 2,7500 & 0,60 & 4,5834 & 1,85 & 2,65 & 2,0371 & 2,10 & 0,60 & 6,08 & 0,15 & 7,31 & 0,8312 & 3,6450 & 0,0180 & 0,0122 & 0,0550 & $\begin{array}{c}\text { Beda Tinggi } \\
\text { Memenuhi }\end{array}$ \\
\hline 9 & 2,7500 & 0,60 & 4,5834 & 2,40 & 3,00 & 1,6975 & 1,70 & 0,60 & 6,21 & 0,13 & 7,04 & 0,8822 & 3,7260 & 0,0180 & 0,0117 & 0,0550 & $\begin{array}{c}\text { Beda Tinggi } \\
\text { Memenuhi }\end{array}$ \\
\hline
\end{tabular}
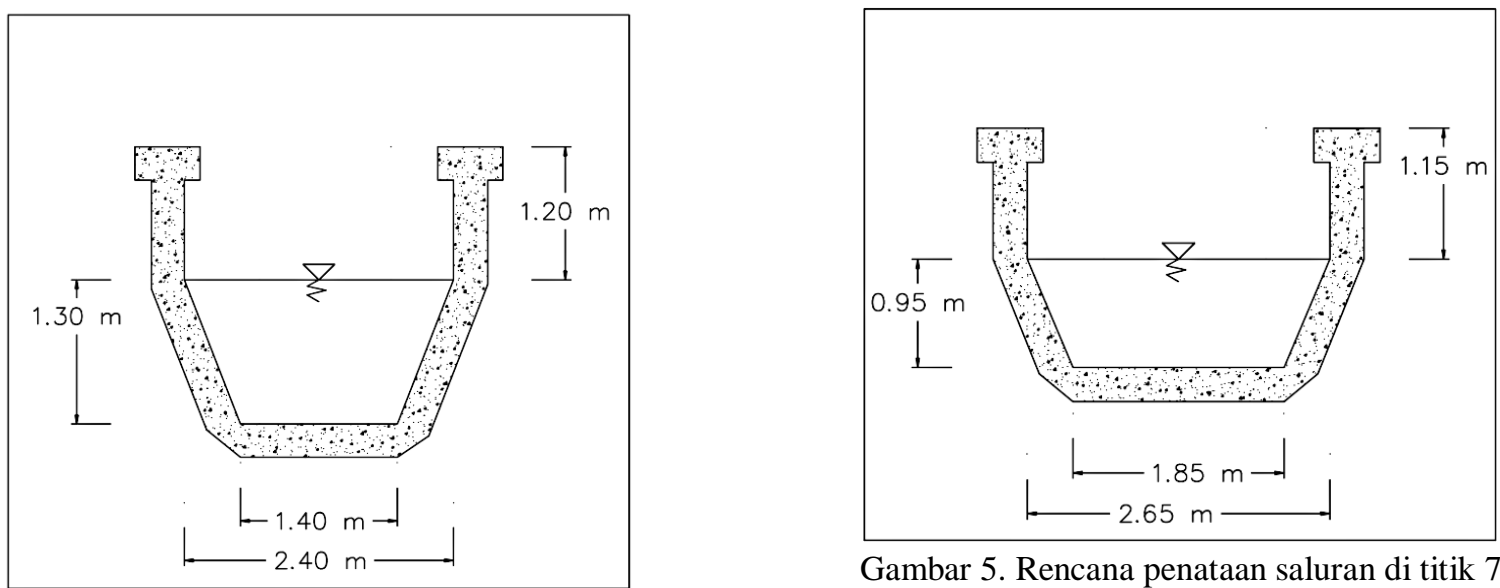

Gambar 5. Rencana penataan saluran di titik 7

Gambar 4. Rencana penataan saluran di titik 1 dan 3 


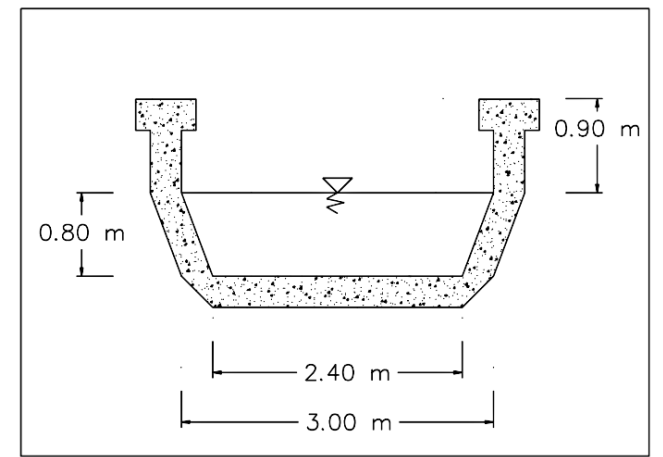

Gambar 6. Rencana penataan saluran di titik 9.

\section{KESIMPULAN DAN SARAN}

\subsection{Kesimpulan}

Debit total di Parit M.Sohor untuk periode ulang 2 tahun adalah $2,22 \mathrm{~m}^{3} / \mathrm{s}$, periode ulang 5 tahun sebesar $2,75 \mathrm{~m}^{3} / \mathrm{s}$ dan periode ulang 10 tahun sebesar 3,09 $\mathrm{m}^{3} / \mathrm{s}$. Debit eksisting di titik 1, 3, 5 dan 9 pada Parit M. Sohor tidak dapat memenuhi debit total di masing-masing periode ulang hujan, sehingga dilakukan penataan drainase dengan cara normalisasi dan membuat penampang saluran disain dengan disain yang mempertahankan kemiringan disain yang ideal dalam mengalirkan air secara cepat. Normalisasi dan membuat penampang saluran disain juga diterapkan pada kondisi saluran eksisting di saluran tersier.

Penataan drainase dengan konsep berwawasan lingkungan mengedepankan penataan drainase yang ramah lingkungan dengan menanam tanaman perdu yang dapat mereduksi polusi udara seperti tanaman Puring dan Bogenvil, menata Jalan M. Sohor agar ramah dengan kaum pedestrian, mengendalikan debit air hujan berlebih yang diakibatkan oleh proses hujan melalui teknik rain water harvesting, menggunakan paving block dengan beton porous pada lahan parkir bangunan serta melakukan pencegahan sedimentasi yang berlebihan dengan cara normalisasi dan pemasangan jaring-jaring kawat di setiap jembatan di atas saluran utama Parit M. Sohor.

\subsection{Saran}

Tata guna lahan di daerah tangkapan hujan harus dijaga keseimbangannya dan diperluas lahan ruang terbuka hijau agar penyerapan air hujan ke dalam tanah dapat lebih banyak agar tidak terjadi run off yang berlebihan. Hal ini juga dapat menghasilkan air tanah yang bermanfaat bagi manusia dalam hal keseimbangan dan kebutuhan air baku.
Normalisasi saluran dengan pengerukan dan pembersihan saluran drainase secara periodik untuk mengantisipasi pendangkalan dan penyempitan saluran drainase sehingga volume sampah di saluran drainase dapat terkendali dan berada di kondisi yang ideal untuk mencegah banjir.

Penghijauan di sekitar jalan M. Sohor dan melakukan penataan tempat pedestrian agar pejalan kaki dapat menikmati kawasan jalan yang berwawasan lingkungan.

\section{Daftar Pustaka}

Agus Fahmudin, Anda Markus, Jamil Ali, Masganti. 2016. Lahan Gambut Indonesia: Pembentukan, Karakteristik, dan Potensi Mendukung Ketahanan Pangan. Badan Penelitian dan Pengembangan Pertanian. Jakarta.

Anonim. 1987. Standar Perencanaan Irigasi, Kriteria Perencanaan Bagian Saluran KP03. Direktorat Jendral Sumber Daya Air Departemen Pekerjaan Umum. Jakarta.

Anonim. 1990. Petunjuk Drainase Permukaan Jalan Nomor 008/T/BNKT/1990.

Direktorat Jendral Bina Marga Direktorat Pembinaan Jalan kota Departemen Pekerjaan Umum. Jakarta.

Anonim. 1996. Analisis Kebutuhan Air Bersih. Departemen Pekerjaan Umum Direktorat Jendral Cipta Karya. Jakarta.

Anonim. 1997. Drainase Perkotaan. Gunadharma. Jakarta.

Anonim. 2004. Strategi Nasional dan Rencana Aksi Pengelolaan Lahan Basah Indonesia. Kementrian Lingkungan Hidup. Jakarta.

Anonim. 2011. Undang-Undang Republik Indonesia Nomor 4 Tahun 2011 Tentang Informasi Geospasial. Badan Informasi Geospasial. Jakarta.

Anonim. 2012. Peraturan Menteri Nomor 5 Tahun 2012 Tentang Pedoman Penanaman Pohon pada Sistem Jaringan Jalan. Pekerjaan Umum Republik Indonesia. Jakarta.

Anonim. 2014. Peraturan Menteri Nomor 12 Tahun 2014 Tentang Penyelenggaraan Sistem Drainase Perkotaan. Menteri Pekerjaan Umum Republik Indonesia. Jakarta.

Anonim. 2017. Kecamatan Pontianak Selatan dalam Angka. Badan Pusat Statistik. Pontianak. 
Anonim.

2019.

Bugenvil.

https://id.wikipedia.org/wiki/Bugenvil.

Diunduh pada tanggal 21 Agustus 2019.

Anonim. 2019.

Puring.

https://id.wikipedia.org/wiki/Puring.

Diunduh pada tanggal 21 Agustus 2019.

Arsyad S. 1985. Strategi Konversi Tanah. Makalah Proceeding Lokakarya Pengelolaan Daerah Aliran Sungai Terpadu. Yogyakarta.

Asdak Chay. 1995. Hidrologi dan Pengelolaan Daerah Aliran Sungai. Gadjah Mada Universty Press. Yogyakarta.

Chow Ven Te. 1997. Hidrolika Saluran Terbuka. Erlangga. Jakarta.

Harto Sri. 2000. Hidrologi Teori-MasalahPenyelesaian. Nafiri Offset. Yogyakarta.

Fadil. 2018. "Bantu Atasi Banjir. Peneliti ITB Terus Kembangkan Geopore Jalan Berpori".

https://www.itb.ac.id/news/read/56688/ho me/bantu-atasi-banjir-peneliti-itb-teruskembangkan-geopore-jalan-berpori. Diunduh tanggal 22 Agustus 2019.

Irianto Gatot. 2003. Banjir dan Kekeringan. Universal Pustaka Media. Bogor.

Kodoatie. Robert J.. 2003. Manajemen dan Rekayasa Infrastruktur. Pustaka Pelajar. Jogyakarta.

Maryono Agus. 2000. Konsep Ekodrainase Sebagai Pengganti Drainase Konvensional. Pusat Penelitian Geoteknologi LIPI. Bandung.

Maryono Agus. 2004. Renaturalisai Sungai di Indonesia. Pusat Penelitian Geoteknologi LIPI. Bandung.

Maulia Iqbal. 2019. Sifat Mekanik Paving Block Komposit Sebagai Lapis Perkerasan Bebas Genangan Air (Permeable Pavement). Universitas Riau. Pekanbaru. Volume 13. pp 9-16.

Meilan. 2015. Pengelolaan Terpadu Daerah Aliran Sungai (DAS). http://mesa26tutor.blogspot.co.id/2015/01/ pengelolaan-terpadu-daerah-aliran.html. Diunduh pada tanggal 18 Agustus 2018.

Mulyani Puji. 2017. Sistem Drainase Yang Berwawasan Lingkungan di Kawasan Urban. Universitas Tanjungpura. Pontianak.

Soemarto C.D. 1995. Hidrologi Teknik. Usaha Nasional. Surabaya.

Soewarno. 1995. Hidrologi Aplikasi Metode Statistik Untuk Analisa Data. Nova. Bandung.
Soewandita Hasmana dan Sudiana Nana. 2011. Analisis Potensi dan Karakteristik Gambut Sebagai Bahan Pertimbangan untuk Arahan Perencanaan Pengembangan Kawasan di Kabupaten Siak. Pusat Teknologi Sumberdaya Lahan Wilayah dan Mitigasi Bencana. BPPT. Jakarta.

Subarkah Imam. 1980. Hidrologi untuk Perencanaan Bangunan Air. Idea Dharma. Bandung.

Sukarto. 1999. Drainase Perkotaan. Mediatama Saptakarya. Jakarta.

Surinati Dewi. 2007. Pasang Surut dan Energinya. Oseana. Volume XXXII. Nomor 1. Hal 15 - 22.

Suripin. 2004. Sistem Drainase Perkotaan Yang Berkelanjutan. Andi. Yogyakarta.

Triatmodjo Bambang. 1996. Pelabuhan. Beta Offset. Yogyakarta.

Triatmodjo Bambang. 2008. Hidrologi Terapan. Beta Offset. Yogyakarta.

Wilson. E.M. 1993. Hidrologi Teknik. Bandung. ITB Press. 